\title{
MULHERES EMPREENDEDORAS: MEDOS, CONQUISTAS E QUALIDADE DE VIDA
}

\author{
Eva Gertrudes Jonathan
}

\begin{abstract}
RESUMO. Face ao desafio de construir conhecimento sobre os aspectos psicológicos envolvidos no empreendedorismo feminino brasileiro, este estudo busca analisar as inquietações e o bem-estar subjetivo de mulheres empreendedoras. Quarenta e nove donas de variados negócios no Rio de Janeiro foram entrevistadas em suas empresas. Uma medida de auto-avaliação mostrou que as empreendedoras compartilhavam uma boa qualidade de vida, fundamentada principalmente na satisfação com o trabalho, com os filhos e com o auto-respeito. Os dados evidenciaram que os múltiplos papéis desempenhados pelas empreendedoras possuem relevância semelhante. A análise qualitativa das entrevistas revelou que as empreendedoras são destemidas e autoconfiantes, embora preocupadas com questões financeiras e com o crescimento das empresas. Autorealizadas, apaixonadas e identificadas com seus empreendimentos, as empreendedoras se percebem num processo contínuo de conquistas. Dificuldades relativas à discriminação de gênero e à multiplicidade de papéis, bem como os demais dados, são discutidos à luz da literatura sobre empreendedorismo feminino.
\end{abstract}

Palavras-chave: empreendedorismo feminino, bem-estar subjetivo, multiplicidade de papéis.

\section{ENTREPRENEURIAL WOMEN: FEARS, ACHIEVEMENTS AND QUALITY OF LIFE}

\begin{abstract}
In face of the challenge to build knowledge on the psychological aspects of gender entrepreneurship in Brazil, this study aims to analyze the worries of entrepreneurial women worries and their subjective well-being. Forty-nine women owning business in various areas of activity in Rio de Janeiro were interviewed at their companies. A self-evaluation measure showed that entrepreneurial women shared an overall high level of quality of life, based mainly on their satisfaction at work, with children and with self-respect. Data indicated that multiple roles played by entrepreneurs are equally relevant. Qualitative analysis of the interviews revealed that those women are fearless and self-confident, though they have worries related to the company financial aspects and growth. Self-satisfied, passionately identified with their firms, they perceive themselves in an achievement continuous process. Problems related to discrimination and to multiple role-playing, as well as all other data are discussed in the light of the literature on gender entrepreneurship.
\end{abstract}

Key words: gender entrepreneurship, subjective well-being, multiple social roles.

Dentro do contexto de um significativo crescimento do trabalho feminino no Brasil (Bruschini, 1994), as mulheres vêm aumentando sua atuação em posições de liderança nas empresas e conquistando mais terreno no espaço público.

No ambiente das micro e pequenas empresas brasileiras, é muito relevante a presença das empresas criadas e lideradas por mulheres, que, dessa maneira, não só constroem para si uma alternativa de inclusão ou permanência no mercado de trabalho, mas também geram empregos e promovem inovação e riqueza, contribuindo para o desenvolvimento socioeconômico do país.

O potencial econômico do empreendedorismo feminino brasileiro é significativo, pois quando se consideram ambos os setores da economia - o formal e o informal - os negócios possuídos por mulheres chegam a constituir quase a metade deste universo (Organization for Economic Co-operation and Development-OECD, 1998). Os dados se confirmam em recente pesquisa que evidencia que há em torno de 6,4 milhões de empreendedoras brasileiras, o que representa $46 \%$ do total de empreendedores brasileiros (GEM, 2003).

Analisando o empreendedorismo feminino existente em diferentes países, Weeks e Seiler (2001) observam que as mulheres empreendedoras da América Latina e do Caribe compartilham muitas características com outras empreendedoras, independentemente da nacionalidade. Além da

* Mestre em Psicologia PUC-Rio. Docente do Departamento de Psicologia da Pontifícia Universidade Católica do Rio de Janeiro, PUC-Rio. 
semelhança quanto aos tipos de negócio mantidos, há semelhanças em relação aos desafios e questões enfrentados pelas empreendedoras para fazer seus negócios crescerem, tais como o acesso à informação, à tecnologia, ao crédito/capital e às redes sociais.

A análise da experiência de mulheres empreendedoras, foco do presente trabalho, orienta-se por uma noção ampla de empreendedorismo. Situado no espaço do trabalho, o termo remete a um processo de, com persistência e visão de futuro, identificar oportunidades e criar algo inovador sob condições de incerteza, assumindo os riscos aí envolvidos (Hisrich \& Peters, 2002). Deste processo resulta a criação de um novo empreendimento ou de uma nova maneira de realizar um trabalho - um novo produto, serviço ou atividade que agrega valor ao que existe e promove benefícios materiais ou sociais. $\mathrm{O}$ termo empreendedorismo é aqui utilizado em sua acepção ampla, remetendo tanto à criação quanto à propriedade e condução de um negócio.

O processo de empreender envolve motivação, atitudes e comportamentos, fatores psicológicos enfatizados na perspectiva teórica aqui adotada, a qual se inspira em múltiplas contribuições, desde os estudos pioneiros de McClelland (1961) aos mais recentes de Moore e Buttner (1997) e de Hisrich e Peters (2002), por exemplo. O presente trabalho objetiva contribuir para a melhor compreensão do empreendedorismo feminino no contexto brasileiro, analisando diferentes aspectos psicológicos que compõem a experiência das empreendedoras.

\section{MULTIPLICIDADE DE PAPÉIS, EMPREENDEDORISMO FEMININO E QUALIDADE DE VIDA}

A multiplicidade de papéis tende a ser considerada uma característica do universo feminino, levando ao reconhecimento de um talento nas mulheres para fazer e pensar várias coisas simultaneamente. No entanto, o acúmulo de tarefas públicas e privadas - rotulado de "dupla jornada" é, freqüentemente, considerado causa ou origem de conflitos e desgastes (Jablonski, 1996; RochaCoutinho, 2003). Em uma perspectiva naturalista, as dificuldades seriam inerentes à multiplicidade de papéis envolvendo demandas concebidas como inconciliáveis em sua natureza.

Pensar diferentemente, quebrar este mito, atentar para a construção social dos papéis de gênero é uma necessidade que se impõe. Pesquisas recentes mostram que mulheres - especificamente mães - que trabalham têm índices mais altos de bem-estar e estão mais satisfeitas do que aquelas que não trabalham (Cherlin, 2001; Vandewater, Ostrove \& Stewart, 1997). Cherlin (2001) observa que uma vida cheia de ocupações, que combine trabalho com maternagem, traz satisfação e sentimento de realização.

No contexto brasileiro, estudos de Jonathan (2001) e de Rocha-Coutinho (2003) sugerem que empreendedoras e executivas, respectivamente, atribuem igual importância à realização profissional, à maternidade, ao relacionamento afetivo estável com um par, bem como ao tempo dedicado a si mesmas. Elas parecem abandonar a idéia de que o sucesso em uma dimensão da vida signifique, necessariamente, fracasso nas demais.

De acordo com Jonathan (2001), alcançar um equilíbrio entre as necessidades vinculadas aos espaços profissional, familiar e pessoal é o que mais desejam as empreendedoras brasileiras, donas de negócios na cidade do Rio de Janeiro. Ao perceberem, por exemplo, que trabalho e família se ajudam e se beneficiam mutuamente, as empreendedoras parecem encontrar um dos caminhos para sustentar tal equilíbrio e obter satisfação. Ao tecerem os vínculos entre afeto e trabalho, produção e reprodução, tal como argumentam Codo, Sampaio e Hitami (1993), as mulheres alcançam o bem-estar subjetivo.

Conclui-se que a multiplicidade de papéis envolvendo o público e o privado pode enriquecer e ser fator de soma, e não de divisão, fragmentação, contradição e estresse. Neste sentido, segundo Possati e Dias (2002), papéis que envolvem autonomia no trabalho e poder de decisão trazem muita satisfação para as mulheres em posição de liderança e são bons preditores do bem-estar psicológico de mulheres casadas.

A meta do presente projeto de investigação é analisar os reflexos dos desafios enfrentados pelas empreendedoras na sua qualidade de vida. No seu aspecto psicológico e de acordo com a Organização Mundial de Saúde, qualidade de vida remete à percepção que o indivíduo tem de sua posição no contexto cultural e no sistema de valores no qual está inserido, tomando como referência seus próprios objetivos, expectativas, padrões e preocupações (Fleck, 2000). Já Maerker (2002) define qualidade de vida como o equilíbrio de todas as áreas do sujeito.

Do ponto de vista conceitual, a questão da qualidade de vida se vincula ao bem-estar subjetivo que é uma de suas dimensões. Segundo Diener (1984), sentir bem-estar subjetivo significa experimentar a vida de forma positiva, julgando que há satisfação com diferentes domínios da experiência vivida tais como o self, o trabalho, a vida familiar, a saúde, o 
contato social, entre outros. Em jogo, portanto, a forma de lidar com a tensão ou o estresse associados aos diversos contextos da experiência vivida.

Em um estudo comparativo, donas de negócios próprios apresentaram maiores índices de satisfação do que executivas (Korn/Ferry, 2002). Ritmo de trabalho, quantidade mínima de interferência de terceiros e interesses pessoais satisfeitos são as principais fontes de satisfação diferenciada das empreendedoras, que se sentem muito comprometidas com seu trabalho. A maior satisfação das empreendedoras se deve ao ambiente do negócio próprio, que lhes proporciona reconhecimento por realizações e autoridade para fazer decisões de impacto, além de possibilitar o desenvolvimento de novas idéias e competências, e, em última análise, a atualização e realização de seus próprios valores e sonhos. Neste sentido, argumentamos que gostar intensamente daquilo que fazem, autonomia no trabalho e poder de decisão são aliados das empreendedoras no exercício dos múltiplos papéis, proporcionando-lhes um sentimento de autorealização.

Por outro lado, de acordo com Csikszentmihalyi (1998), o bem-estar subjetivo é produto concomitante da ação e, portanto, o contentamento decorre da atividade em si e não do atendimento de metas. $\mathrm{O}$ autor propõe o conceito de fluxo para expressar a adequação perfeita, geradora de satisfação, entre a magnitude dos desafios enfrentados e a habilidade para lidar com eles. A sensação de fluir diz respeito ao próprio processo de enfrentar obstáculos, à experiência em si, mais do que ao sentimento de ter vencido ou alcançado determinado objetivo.

O conceito de fluxo é interessante para significar a vivência do trabalho que as mulheres empreendedoras têm. Julgamos, então, que o trabalho realizado pelas empreendedoras constitui um espaço que favorece seu crescimento pessoal, na medida em que os desafios que enfrentam as induzem a desenvolver competências adequadas para lidar com eles. Por outro lado, quando os desafios começam a requerer pouco envolvimento e atenção é hora de ir em busca de novos desafios. Satisfação com a vida é resultante do processo dinâmico de adequação entre desafios e competências, entre forças externas e internas: quanto melhor a adequação, maior a satisfação. Supõe-se, ainda, que esta adequação é influenciada positivamente pelo alto grau de autonomia e liberdade de decisão envolvido na atividade de trabalho de mulheres que escolheram criar e conduzir os seus próprios negócios. Ao contrário, medos e preocupações constrangem as competências, dificultando o adequado enfrentamento dos desafios e a vivência de bem-estar subjetivo.

O presente estudo busca examinar a questão do bem-estar subjetivo e da qualidade de vida de mulheres empreendedoras e contribuir, assim, para a compreensão da dimensão de gênero no contexto do empreendedorismo brasileiro. Nesse sentido, busca-se analisar ganhos e custos psicológicos vivenciados pelas empreendedoras à luz da multiplicidade de papéis que desempenham.

\section{MÉTODO}

O estudo foi realizado com uma amostra de conveniência constituída de 49 empreendedoras cariocas, atuando em diferentes setores da economia. Alguns critérios nortearam a seleção das participantes do estudo: posse de uma empresa não franqueada e em atuação no mercado há pelo menos um ano; significativa participação acionária no empreendimento; envolvimento ativo no diaa-dia da empresa; desempenho de função de liderança administrativa e/ou técnica.

A abordagem metodológica foi estruturada com o objetivo de revelar a compreensão que as próprias mulheres tinham de suas experiências como empreendedoras. No primeiro contato com as empreendedoras, realizado por telefone ou pessoalmente, foi-lhes feito um convite para participar de uma pesquisa sobre a experiência das empreendedoras brasileiras. As empreendedoras mostraram-se muito receptivas à investigação, concordando em ser entrevistadas em suas empresas.

Inicialmente, as empreendedoras preencheram um questionário com dados descritivos pessoais e da empresa. Em seguida, realizaram-se entrevistas semi-estruturadas, fundamentadas em um roteiro com 13 questões abertas e com a duração de aproximadamente 45 minutos. Medos e preocupações, bem como fontes de satisfação e insatisfação, focos principais dos dados relatados no presente trabalho, constituíram dois dos cinco temas abordados na entrevista. As demais temáticas discutidas foram: trajetória e motivação; conflitos e formas de enfretamento e conseqüências de ser empreendedora.

As entrevistas duraram cerca de 45 minutos e foram gravadas com o consentimento das participantes. Ao final das entrevistas, as empreendedoras responderam ao Inventário de Qualidade de Vida - Quality of Life Inventory - QOLI de Frisch (1992), instrumento originalmente concebido em 1988 e analisado no Brasil por Fleck (2000). O instrumento proporciona uma medida de qualidade de vida expresso pela média de todas as avaliações de satisfação em relação às diversas 
dimensões do espaço vital consideradas importantes pelos respondentes. Para fins deste estudo, foi introduzido um item voltado para avaliar relações com os funcionários e outro para avaliar relações institucionais.

As fitas com as entrevistas gravadas foram transcritas, sendo o material submetido a uma análise do discurso cuja metodologia contemplou tanto um exame transversal do conteúdo (entre participantes) quanto um exame vertical (de cada participante). $\mathrm{O}$ material recorrente que emergiu destas análises foi organizado em categorias.

\section{RESULTADOS}

Os resultados foram organizados em diferentes tópicos e são apresentados a seguir. Para facilitar sua apreensão, as categorias que emergiram da análise do discurso estão grafadas em itálico no texto, e são ilustradas com trechos das falas das empreendedoras.

\section{Sobre as empreendedoras e suas empresas.}

Os resultados indicaram que as empreendedoras eram muito escolarizadas, sendo que $61,2 \%$ possuíam o nível superior completo. Uma formação na área humana/social/médica foi observada na maioria das empreendedoras $(55,1 \%)$. A amostra envolveu mulheres maduras, que tinham em média 46,5 anos, sendo $68,7 \%$ casadas, $18,7 \%$ solteiras e $12,5 \%$ separadas.

Em consonância com o estado conjugal e a idade das empreendedoras, $83,7 \%$ delas tinham filhos (média de 2,1 filhos) e, entre estes, 65,9\% tinham mais de 18 anos, $18,2 \%$ entre 12 e 18 anos, e somente $15,9 \%$ tinham menos de 12 anos. Quase todas as empreendedoras contavam com ajuda nos cuidados com o lar (64,4\% tinham o apoio de empregados e $28,8 \%$ eram ajudadas por familiares).

Em relação aos empreendimentos, os dados indicaram que $55,36 \%$ das empresas atuavam no setor de serviços; 33,93\% encontravam-se no setor do comércio e 10,71\% na área industrial. As empresas, comandadas em média por 2,3 sócios, tendiam a estar bem estabelecidas no mercado, possuindo em média 9,7 anos de atuação. Em geral, eram microempresas, possuindo em média 8,9 funcionários.

Observou-se que as empreendedoras estavam profundamente envolvidas nas empresas, quer porque tinham, em média, 63,2\% de participação acionária quer porque a elas dedicavam, em média, 10,4 horas diárias. Os resultados mostraram, também, que 46,9\% das empreendedoras gostariam de manter o número de horas dedicadas, ao passo que 40,8\% gostariam de dedicar menos horas e $12,2 \%$ desejavam aumentar sua dedicação diária aos negócios. Portanto, para uma parcela das empreendedoras, o tempo dedicado à empresa parece estar na contramão do desejo, podendo se configurar como uma fonte de insatisfação. A questão será retomada mais adiante.

\section{Medos, preocupações e conquistas.}

As empreendedoras tenderam a ser otimistas e assertivas, afirmando que o empreendedorismo envolve ausência de medo, como ilustram suas falas:

"Não, nada me causa medo, de jeito nenhum...tem que acreditar, acreditar, fazer acontecer e pronto..." (51 anos, atuação no comércio)

"Medo é uma palavra que não existe no nosso vocabulário...Não pode existir medo se você é empreendedor..." (47 anos, atuação no comércio)

No entanto, observou-se que o sentimento de medo, quando existente, não paralisava as empreendedoras, estando por vezes associado a aspectos financeiros e à própria sobrevivência da empresa:

\footnotetext{
“Às vezes me dá medo. É aquele negócio ...; são as dívidas...será que vai acontecer alguma coisa de ter que fechar..." (26 anos, atuação em serviços)
}

Também o crescimento da empresa amedrontou algumas empreendedoras, seja pela ameaça de perda de qualidade seja pela insegurança quanto ao retorno financeiro correspondente:

\footnotetext{
"Crescer....quando a gente começa a crescer muito as coisas fogem do controle de qualidade que a gente gostaria de manter..." (46 anos, atuação em serviços)

"O medo de crescer, de fazer um novo investimento com essa instabilidade do país, dá um certo medo. Me dá pânico." (28 anos, atuação em comércio)
}

Complementando o quadro das inquietações generalizadas existentes no mundo dos negócios, muitas empreendedoras revelaram sua preocupação um sentimento mais difuso do que o medo - com as finanças, com as condições sociopolítico-econômicas do país, bem como com a satisfação dos clientes, 
como ilustram, correspondentemente, seus depoimentos:

"Existe (preocupação). e muita; são as contas, ...impostos, encargos, ,....a não ser que se trabalhe na ilegalidade..." (52 anos, atuação em serviços)

“(Preocupa) o país...regras que não valem mais no dia seguinte...o custo Brasil é muito alto..." (67 anos, atuação em indústria, comércio e serviços)

"A minha preocupação maior é atender ao cliente..." (51 anos, atuação em serviços)

Contrastando com medos e preocupações, as empreendedoras expressaram sentimentos de clara conquista e vitória. Como observado anteriormente, tenderam a assumir uma postura assertiva, percebendo-se como vencedoras, o que foi vivenciado como um processo dinâmico e contínuo, e não como um ponto de chegada:

"Acho que sim (sou vencedora). Mas acho
que ser vencedora é uma batalha
diária...Você é uma vencedora a cada dia."
(34 anos, atuação em serviços)
“...considero que a gente tem vencido várias
etapas e vem construindo e acho que não sou
vencedora e acabei e pronto... até o
determinado momento me considero
vencedora com certeza." ( 30 anos, atuação
em serviços)

As empreendedoras demonstraram orgulho de suas realizações e o sentimento de vitória se expressou ora por serem alvo de reconhecimento pessoal:

“...(vencedora) por toda a trajetória que tive de vida ... não foi fácil não, ....mas tem gente que chega para mim e diz que sou 'ídola' deles; então é muito bacana pessoas considerarem você" (60 anos, atuação no comércio),

ora pelo sucesso no desempenho de seus múltiplos papéis, alcançado por algumas:

"Eu acho que eu me considero uma vencedora, porque em tudo, eu acho que em tudo, eu consigo conciliar a minha vida, o meu marido, a vida com os meus filhos, a minha vaidade, as minhas atividades pessoais...Eu acho que o equilíbrio é uma vitória..." (34 anos, atuação em indústria)
Ao se discutir o bem-estar psicológico das empreendedoras, faz-se necessário abordar os ganhos e as perdas envolvidos. A próxima seção descreve com mais detalhes as fontes de satisfação e insatisfação das empreendedoras.

\section{Qualidade de vida}

A qualidade de vida das empreendedoras foi avaliada em função da percepção que elas próprias tinham de seu bem-estar subjetivo. A análise dos dados quantitativos do Inventário de Qualidade de Vida revelou que, de um modo geral, as empreendedoras estavam bastante satisfeitas com as diferentes dimensões de seu espaço vital (média 3,6). Observando-se que o grau de satisfação podia variar de -6 a +6 , a Tabela 1 mostra o índice de satisfação geral com a vida, bem como os índices de satisfação em relação a cada uma das dimensões vitais.

Tabela 1. Índices de satisfação com a vida

\begin{tabular}{lcc}
\hline Dimensões & Média & DP \\
\hline Saúde & 3,1 & 3,3 \\
Respeito Próprio & 4,7 & 2 \\
Filosofia de vida & 4,4 & 2,1 \\
Padrão de Vida & 3 & 2,4 \\
Trabalho & 5 & 1,5 \\
Recreação & 2,2 & 2,9 \\
Aprendizagem & 4 & 2,1 \\
Criatividade & 4,1 & 2,3 \\
Ação Social & 2,2 & 3 \\
Ação Cívica & 2 & 2,8 \\
Relações Amorosas & 4,1 & 2,2 \\
Amizades & 4,5 & 2 \\
Filhos & 5 & 1,3 \\
Parentes & 3,8 & 2,4 \\
Funcionários & 4,3 & 1,8 \\
Rel. Institucionais & 3 & 2,5 \\
Lar & 4,4 & 2,1 \\
Vizinhança & 2,6 & 2,8 \\
Comunidade & 2,8 & 2,4 \\
\hline Geral & 3,6 & 2,3 \\
\hline
\end{tabular}

Verificou-se que os maiores índices de satisfação estavam vinculados, primordialmente, ao trabalho e à relação com os filhos (ambos com média 5), bem como ao respeito próprio (média 4,7). Em contrapartida, ação cívica (média 2), seguida de recreação e de ação social (ambas com média 2,2) apresentaram os menores índices de satisfação. Foi observado, também, que embora o grupo como um todo apresentasse certa satisfação quanto à saúde (média 3,1; DP 3,3), em torno de 16,3\% das 
empreendedoras manifestaram clara insatisfação (médias negativas).

\section{Fontes de satisfação}

Auto-realização. A análise do discurso das empreendedoras possibilitou aprofundar a compreensão acerca do valor e significado atribuídos por elas às fontes de satisfação/insatisfação vinculadas a sua experiência como empreendedoras. Primeiramente, foi observado que tal vivência, ao ser comparada com experiências anteriores de trabalho, era marcantemente caracterizada pelo sentimento de auto-realização, refletindo-se positivamente na autoestima, como pode ser visto nos seguintes depoimentos:

“...a minha auto-estima melhorou...A gente pensa, elabora uma idéia, desenvolve, põe em prática... quando dá certo, você se sente supercapaz ...E nas outras vezes que eu era funcionária, por mais que eu me dedicasse, eu não achava que era mérito meu..." (43 anos, atuação em serviços)

Criatividade e afirmação dos próprios valores. Os dados indicaram que as empreendedoras maciçamente valorizaram a autonomia e a independência, fatores associados à liberdade para ter iniciativas e para criar e desenvolver idéias, os quais possibilitam imprimir ao trabalho sua marca pessoal:

"A independência...A satisfação de ser a dona de meu próprio nariz é uma coisa muito, muito, muito boa...é impagável" (63 anos, atuação na indústria)

"Extremamente gratificante (ser empreendedora), porque primeiro eu tenho a iniciativa de fazer as coisas na hora que eu quero e da forma que eu quero. ... posso gerenciar da minha forma" (56 anos, atuação na indústria)

"Eu gosto de fazer realizar minhas idéias com liberdade de expressão,...ter uma independência, fundamental para quem tem vontade de criar no trabalho." (36 anos, atuação no comércio)

Identificação. As empreendedoras expressaram profundo investimento afetivo nos seus negócios: "paixão pelo que está lá dentro". Para muitas, a satisfação provinha da sintonia afetiva entre o empreendimento e o que apreciavam fazer:
"Agora eu me sinto muito mais satisfeita, porque, além de fazer o que eu gosto, da maneira que eu gosto...estou fazendo uma coisa com que me identifico..." (47 anos, atuação no comércio)

Satisfação dos clientes e Reconhecimento do mercado. Os dados mostram que as empreendedoras tenderam a perceber a satisfação dos clientes, bem como a ampla aceitação externa obtida, como fontes importantes de sua própria satisfação:

“...sem dinheiro é impossível se manter, mas a minha maior satisfação é ver que o cliente gosta..." (51 anos, atuação em serviços)

“...(satisfação) é você estar no mercado; é você ser reconhecido no mercado..." (42 anos, atuação em serviços)

"É ver o produto que você lança ter uma saída grande. Quando você vê um 'chef' desses franceses que compram e vêm te elogiar...vou a um jantar, ...vejo só o pessoal elogiar." (56 anos, atuação no comércio e na indústria)

Vale assinalar, ainda, que somente umas poucas empreendedoras apontaram a flexibilidade de horário como fundamento para a satisfação, o que desfaz uma difundida noção em relação ao negócio próprio.

Por fim, para melhor apreender a qualidade de vida das empreendedoras é necessário também analisar os fatores que não concorrem para o seu bemestar subjetivo, mas, ao contrário, contribuem para sua insatisfação.

\section{Fontes de insatisfação}

Os resultados mostraram que as empreendedoras basearam sua insatisfação em um conjunto de fatores. Inicialmente, é necessário colocar que, por vezes, os clientes foram vistos como fonte de estresse: seus humores, suas manhas, suas exigências causavam dissabores. Dessa forma, a clientela se configura como uma moeda de dois lados: tem o potencial para causar satisfação e insatisfação nas empreendedoras.

Qualificação dos funcionários. Embora as empreendedoras freqüentemente reconhecessem $o$ valor positivo de sua equipe, foram bastante generalizadas as afirmações relativas à insatisfação com o desempenho dos funcionários:

“...principalmente o nível intelectual, de entendimento dos meus, de alguns funcionários..." (43 anos, atuação em serviços) 
“...aliás eu gostaria e teria condições de ampliar o meu negócio se eu tivesse mão-deobra qualificada..." (47 anos, atuação no comércio e em serviços)

Retorno financeiro. As empreendedoras reconheceram que a questão financeira era uma fonte de tensão, acarretando insatisfação:

“....essa de você não ter retorno financeiro; é muito lento o retorno... ganhei muito até, mas não tem muita tranqüilidade financeira no meu negócio" (45 anos, atuação no comércio)

As empreendedoras também fizeram diversas menções ao Governo, envolvendo impostos, legislação e situação financeira do país.

Apesar de não terem sido abordadas com muita freqüência, duas questões adicionais merecem atenção por envolverem aspectos do universo feminino. A primeira remete à questão da discriminação e a segunda vem ao encontro da multiplicidade dos papéis desempenhados pelas empreendedoras.

Discriminação. Poucas empreendedoras experimentaram barreiras devido a seu gênero. A discriminação se revelou, então, como uma fonte de mal-estar superada:

“...senti uma certa rejeição...fui com o P. em algumas reuniões...mas as pessoas se dirigiam a ele, e não se dirigiam a mim. Aí eu acostumei, passou a não me incomodar mais..." (45 anos, atuação no comércio)

“...precisei me impor para que eles pudessem acreditar, e depois eles ficam macios. A discriminação foi mais no início" (55 anos, atuação em serviços)

Multiplicidade de papéis. Os resultados indicaram que algumas empreendedoras reconheceram certas dificuldades na atualização da multiplicidade de papéis: “...eu queria ter um pouco mais de tempo para mim...para ler... visitar a minha filha...quero ter tempo para cuidar de mim,...fazer unha, cabelo, ir à terapia...O tempo é muito angustiante." (48 anos, atuação em serviços)

\section{DISCUSSÃO}

De forma ampla, tanto o perfil pessoal das empreendedoras quanto o perfil das empresas foram semelhantes aos encontrados por outras pesquisas realizadas no Brasil (Jonathan, 2001; Jonathan, 2003; Machado, Barros \& Palhano, 2003): as empreendedoras tendem a ser escolarizadas, maduras em idade, casadas, com filhos; os empreendimentos tendem a ser microempresas atuando predominantemente no setor de serviços, que contam com uma significativa participação acionária das empreendedoras que a elas se dedicam com afinco.

$\mathrm{O}$ destemor e a autoconfiança presentes nos discursos das empreendedoras reproduzem o que inúmeros pesquisadores observaram serem características do perfil do empreendedor, independentemente de gênero ou de nacionalidade (Hisrich \& Peters, 2002; Weeks \& Seiler, 2001). Mas os resultados sugerem que questões financeiras e o crescimento da empresa suscitam inseguranças e levam as empreendedoras brasileiras a um comportamento de cautela face ao desenvolvimento do negócio, também observado nas empreendedoras da área tecnológica (Jonathan, 2003).

Embora haja inquietações e inseguranças, as empreendedoras se sentem vitoriosas. Sua percepção de sucesso é especialmente nítida quando alcançam certo equilíbrio - ainda que instável - entre as diversas demandas vinculadas à multiplicidade de papéis, corroborando as observações de Jonathan (2001). As empreendedoras vivenciam, ainda, um processo contínuo de conquistas face aos desafios enfrentados. Seu bem-estar subjetivo e sua satisfação parecem provir da própria ação, mais do que do atendimento de metas (Csikszentmihalyi, 1998). Há indícios do que o autor chamou de fluxo, na medida em que as empreendedoras experimentam um processo bemsucedido de contínua adequação entre os desafios enfrentados e suas habilidades para lidar com eles.

A constatação, com dados quantitativos, de que as principais fontes de satisfação provinham do trabalho, dos filhos e do respeito próprio reafirma a relevância e o prazer associados quase que igualmente ao espaço profissional, ao familiar e ao pessoal. As 
empreendedoras experimentam positivamente diversas dimensões de seu espaço vital, o que, segundo Diener (1984), é indicador de bem-estar subjetivo. A multiplicidade de papéis tem, pois, um efeito de somar fontes de satisfação e produzir qualidade de vida.

Não obstante, faz-se necessário discutir a relativamente pouca satisfação quanto à recreação, à ação cívica, à ação social e, de certa forma, em relação à saúde, um aspecto que suscitou muita insatisfação em uma parcela das empreendedoras. Embora o aprofundamento da questão requeira outros estudos, os dados sugerem que estas áreas não estão sendo atendidas adequadamente. A qualidade de vida das empreendedoras se beneficiaria com um resgate destas dimensões.

Autonomia no trabalho e poder de decisão são invocados pelas empreendedoras como promotores de muita satisfação e bem-estar psicológico, tal como assinalado por Possati e Dias (2002). As empreendedoras enfatizaram também que autorealização, criatividade e afirmação dos próprios valores, além da identificação com a empresa, constituíam importantes fontes de sua satisfação. Existe um diferencial na experiência das donas de negócios quando comparadas com as executivas (Korn/Ferry, 2002), e os dados reforçam a idéia de que o empreendedorismo constitui um terreno favorável ao bem-estar subjetivo das mulheres. Alicerçada em diversificadas bases, a qualidade de vida das empreendedoras se enriquece com a sua experiência de trabalho.

Por outro lado, dissabores com funcionários foram acompanhados por um sentimento de grande responsabilidade para com aqueles que delas dependiam, levando as empreendedoras a se empenhar em oferecer aos empregados treinamentos e benefícios. A postura das empreendedoras diante das fontes de insatisfação - não só a que remete aos funcionários - parece ser a de transformar carências e dissabores em desafios, que, enfrentados e superados, podem resultar em fontes de satisfação.

Outras fontes de insatisfação observadas remeteram à insegurança econômica, confirmando dados de Korn/Ferry (2002), bem como às questões que envolvem ações governamentais. Neste contexto, o discurso das empreendedoras reitera o que é de conhecimento geral e que, independentemente de gênero, atinge a todos os empreendedores brasileiros: no Brasil, há entraves e barreiras ao desenvolvimento do empreendedorismo que clamam por políticas públicas mais adequadas.

Quanto às questões que atingem especificamente as mulheres, os dados confirmam as observações de
Jonathan (2003): de um lado, as empreendedoras são bastante assertivas ao lidar com a sua condição feminina; de outro, a quebra de estereótipos e preconceitos envolvendo donas de negócios próprios é um processo em andamento.

Por sua vez, a questão da multiplicidade de papéis se mostrou bastante problematizada pelas empreendedoras. Enquanto algumas se sentem vencedoras por terem conseguido estabelecer certo equilíbrio entre as demandas, outras afirmam ter melhorado na forma de lidar com os desafios concomitantes. Já a realidade de algumas outras é caracterizada pela busca (ainda sem encontrar) de adequadas estratégias de conciliação, que possibilitem, por exemplo, atender ao próprio desejo de diminuir as horas dedicadas ao trabalho.

$\mathrm{O}$ conjunto de dados sugere que o empreendedorismo proporciona sólidas fontes de satisfação às mulheres. Sua postura assertiva e até mesmo otimista em face da multiplicidade de papéis e da busca de harmonização entre diferentes demandas pode ser inspiradora para outros agentes sociais, pois, em última análise, estão em jogo condições culturais da pós-modernidade (Bauman, 1998). As empreendedoras revelam caminhos possíveis para o trânsito entre o espaço público e o privado, vinculando afeto e trabalho, produção e reprodução, como proposto por Codo e cols. (1993).

\section{CONSIDERAÇÕES FINAIS}

A participação das mulheres no empreendedorismo brasileiro é muito significativa e demanda uma melhor compreensão das questões enfrentadas pelas empreendedoras e dos reflexos destas na sua qualidade de vida.

$\mathrm{O}$ presente estudo revela o alto grau de comprometimento das empreendedoras com as suas empresas. Elas demonstram ser destemidas e autoconfiantes, embora preocupadas com aspectos financeiros, com o crescimento da empresa, bem como com a satisfação dos clientes e as condições sociopolítico-econômicas do país. Seus medos e preocupações tendem a ficar esmaecidos diante do forte sentimento de conquista. Orgulhosas de suas realizações, as empreendedoras se sentem vitoriosas, ora pelo reconhecimento pessoal de que são alvo, ora pelo sucesso alcançado na afirmação de seus múltiplos papéis.

De forma geral, é boa a qualidade de vida das empreendedoras. Trabalho, filhos e respeito próprio são - quase igualmente - geradores de altos índices de satisfação, indicando que o espaço profissional, o 
familiar e o pessoal influenciam positivamente o bemestar psicológico das empreendedoras.

A experiência de ser empreendedora proporciona satisfação às mulheres pois é mediadora de um forte sentimento de auto-realização, que se reflete em uma alta auto-estima. Por outro lado, sua grande satisfação decorre do fato de que o negócio próprio é algo com que se identificam, ao qual se dedicam com paixão e que lhes possibilita criar e afirmar seus próprios valores, na medida em que há autonomia, independência e liberdade para ter iniciativa e desenvolver idéias. Complementarmente, as empreendedoras derivam sua própria satisfação da satisfação dos clientes e do reconhecimento manifestado pelo mercado.

Em que pese a tudo isso, o exercício do empreendedorismo feminino não é fácil: há ganhos e perdas. Quais são, então, as fontes de insatisfação? Ação cívica, recreação e ação social são dimensões do espaço vital das empreendedoras que promovem relativamente baixos índices de satisfação. A estes fatores se acrescenta o fato de a dimensão saúde ser produtora de muita insatisfação para algumas mulheres. A questão requer aprofundamento, mas o conjunto de observações sugere que as empreendedoras ganhariam em qualidade de vida com um melhor atendimento destas dimensões.

No âmbito do exercício de empreender, outros fatores geram insatisfação nas mulheres: qualificação dos funcionários, retorno financeiro e ações governamentais. Tendo em vista a especificidade do universo feminino, observou-se que a discriminação de gênero é uma fonte de mal-estar que ainda atinge algumas empreendedoras. Já o exercício da multiplicidade de papéis mostra ser uma questão cercada de certa ambivalência, uma vez que ora está associada a um sentimento de vitória e realização, ora a um sentimento de frustração ou de angústia. Entretanto, a postura assertiva e de afirmação da relevância simultânea de variadas dimensões do espaço vital, observada nas empreendedoras, faz supor que o exercício do empreendedorismo, apoiado em autonomia e poder de decisão, coloca as mulheres em condição de transformar as dificuldades e insatisfações em desafios capazes de gerar satisfação.

Cabe, não obstante, lembrar que o equilíbrio entre o público e o privado não deve ser algo a ficar a cargo unicamente das mulheres. Se é fato que as mulheres vêm modificando seus papéis sociais e encontrando novas e criativas estratégias para lidar com a multiplicidade de papéis, os homens também são levados a fazê-lo, o que implica em sua maior participação na condução da casa.
$\mathrm{Na}$ verdade, a própria sociedade precisa realinhar o mundo do trabalho com a realidade da vida familiar contemporânea. Como propõe Halpern (2004), para que a interação trabalho-vida funcione são necessários novos modelos, que possibilitem maiores índices de satisfação tanto para os homens quanto para as mulheres.

\section{REFERÊNCIAS}

Bauman, Z. (1998). O mal-estar na pós-modernidade. Rio de Janeiro: Zahar.

Bruschini, C. (1994). O trabalho da mulher no Brasil: tendências recentes. Em H.I.B. Saffioti \& M. Muñoz-Vargas (Orgs), Mulher brasileira é assim. Rio de Janeiro: Rosa dos Ventos, pp. 63-93.

Cherlin, A. J. (2001, 3a. ed). Public and private families: an introduction. New York: Mc Graw Hill.

Codo, W., Sampaio, J. J. C. \& Hitomi, A. H. (1993). Indivíduo, trabalho e sofrimento: uma abordagem interdisciplinar. Petrópolis, RJ: Vozes.

Csikszentmihalyi, M. (1998). The psychology of everyday life. London: Phoenix.

Diener, E. (1984). Subjective well-being. Psychological Bulletin, 95, 542-575.

Fleck, M. P. A. (2000). O instrumento de avaliação de qualidade de vida da Organização Mundial de Saúde(WHOQOL-100): características e perspectivas. ABRASCO-Associação Brasileira de Pós-graduação em Saúde Coletiva, 5(1), 33-38.

Frisch, M. B. (1992). Test manual and treatment guide for quality of life inventory. Waco, Texas: Autor.

GEM - Global Entrepreneurship Monitor. Empreendedorismo no Brasil. Sumário Executivo. IBPQ/SEBRAE/IEL. 2003. Disponível em <http://www.sebrae.com.br/br/ued/download/gem_2003.pdf> (Acessado em 15/03/2004)

Halpern, D. (2004). Making it work: recommendations for policies on working families. Monitor on Psychology, 35(3), 5.

Hisrich, R. D. \& Peters, M. P. (2002, 5 ed.). Entrepreneurship. Boston, MA: Irwin/McGraw Hill.

Jablonski, B. (1996). Papéis conjugais: conflito e transição. Relação amorosa, casamento, separação e terapia de casal, Coletâneas da ANPEPP, 1, 113-123.

Jonathan, E. G. (2001). Mulheres empreendedoras: quebrando alguns tabus. Em III Encontro Nacional de Empreendedorismo(ENEMPRE). Anais do Encontro. Florianópolis: USFC (CD-ROM).

Jonathan, E. G. (2003). Empreendedorismo feminino no setor tecnológico brasileiro: dificuldades e tendências. $\mathrm{Em} 3^{\circ}$ EGEPE-Encontro de Empreendedorismo e Gestão de Pequenas Empresas, Anais do Encontro. Brasília: UEM/UEL/UnB, 4153.

Korn/Ferry International (2002). What women want in business: a survey of executives and entrepreneurs. Autor. Disponível em: <http://www.kornferry.com/library/Process.asp? $p=P U B \_004>$ (Acessado em 14/10/2003) 
Machado, H. P. V., Barros, G. V.\& Palhano, D. Y. M. (2003). Conhecendo a empreendedora norte-paranaense: perfil, porte das empresas e dificuldades de gerenciamento. Em $3^{\circ}$ EGEPEEncontro de Empreendedorismo e Gestão de Pequenas Empresas, Anais do Encontro. Brasília: UEM/UEL/UNB, 171197.

McClelland, D. C. (1961). The achieving society. Princeton, New Jersey: Van Nostrand.

Maerker, S. (2002). Como equilibrar a correria do cotidiano com o stress. Disponível em: < http://www.telecompare.com.br/inputer_view.phtml?id=4651> Acessado em 22/08/2002.

Moore, D. P. \& Buttner, E.H. (1997). Women entrepreneurs: moving beyond the glass ceiling. Thousand Oaks, CA: Sage Publications.

Organization for Economic Co-operation and Development OECD (1998). Women entrepreneurs in SMEs: a major force in innovation and job creation, Synthesis. Paris: Autor.

Possatti, I. C. \& Dias, M. R (2002). Multiplicidade de papéis da mulher e seus efeitos para o bem-estar psicológico. Psicologia Reflexão e Crítica,15(2), 293-301.
Rocha-Coutinho, M. L. (2003). Quando o executivo é uma "dama": a mulher, a carreira e as relações familiares. Em T. F. Carneiro (Org.), Família e casal: arranjos e demandas contemporâneas (pp. 57-77). Rio de Janeiro: Editora PUCRio/Loyola.

Vandewater, E. A., Ostrove, J. M. \&. Stewart, A. J (1997). Predicting women's well-being in midlife: the importance of personality development and social role involvements. Journal of Personality and Social Psychology, 72(5), 1147-1160.

Weeks, J. R. \& Seiler, D. (2001). Women's entrepreneurship in Latin America: an exploration of current knowledge. Washington, DC: Inter-American Development Bank.

Recebido em 09/02/2005 Aceito em 30/08/2005

Endereço para correspondência: Eva Gertrudes Jonathan, Rua Sambaiba, 478/401, CEP 22450-140, Rio de Janeiro-RJ.

E-mail: evajonat@psi.puc-rio.br 